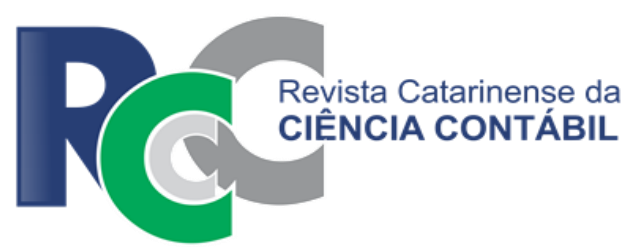

\title{
ANÁLISE DO IMPACTO DAS VARIÁVEIS MACROECONÔMICAS NO DESEMPENHO ECONÔMICO-FINANCEIRO DAS EMPRESAS DOS SETORES DE CONSUMO CÍCLICO E NÃO CÍCLICO DA BM\&FBOVESPA
}

\author{
ANALYSIS OF THE IMPACT OF MACROECONOMIC VARIABLES ON THE \\ FINANCIAL PERFORMANCE OF COMPANIES IN THE SECTORS OF CONSUMER \\ CYCLICAL AND NON-CYCLICAL OF BM\&FBOVESPA
}

\begin{abstract}
JARDEL PANDINI
Graduado em Ciências Contábeis pela Universidade do Estado de Santa Catarina (UDESC). Endereço: Rua Braulino Guimarães, 36 / Gabiroba / 88400-000 / Ituporanga/SC / Brasil.

E-mail: jardelpandini@hotmail.com

\section{DIEGO RAFAEL STÜPP}

Mestre em Contabilidade pela Universidade Federal de Santa Catarina (UFSC). Professor da Universidade do Estado de Santa Catarina (UDESC). Endereço: Rua João Custódio da Luz, 43 / Progresso / 89163-766 | Rio do Sul/SC | Brasil.

E-mail: diego.stupp@udesc.br

VALKYRIE VIEIRA FABRE

Mestra em Contabilidade pela Universidade Federal de Santa Catarina (UFSC). Professora da Universidade do Estado de Santa Catarina (UDESC). Endereço: Rua Siegolf Radloff, 76 / Ponto Chic / 89140000 | Ibirama/SC / Brasil.

E-mail: valkyrie.fabre@udesc.br
\end{abstract}

\section{RESUMO}

Todas as empresas sofrem influência das variáveis macroeconômicas, de forma mais ou menos acentuada, uma vez que estão sujeitas às condições econômicas das regiões onde estão inseridas. Esse raciocínio não é diferente para empresas que vendem bens e serviços aos consumidores finais, tais como as empresas pertencentes ao setor de Consumo Cíclico (produção e venda de bens duráveis) e Não Cíclico (produção e venda de bens não duráveis) da BM\&FBovespa. À luz da Teoria dos Ciclos Econômicos, o objetivo do presente trabalho foi verificar o impacto das variáveis macroeconômicas nos indicadores econômico-financeiros das empresas do setor de Consumo Cíclico e Não Cíclico da BM\&FBovespa, uma vez que a teoria sugere que empresas do primeiro setor são mais afetadas por flutuações econômicas do que empresas do segundo setor. Nesse sentido, realizou-se uma pesquisa quantitativa, descritiva e com análise de dados documentais. O estudo utilizou-se do cálculo dos coeficientes de correlação canônica, com o auxílio do software estatístico SPSS (Statistical Package for the Social Sciences). A amostra da pesquisa consistiu em 103 empresas que negociam seus papéis na BM\&FBovespa, divididas nos setores de Consumo Cíclico (64 empresas) e Consumo Não Cíclico (39 empresas). As conclusões do estudo apontam para uma aceitação da teoria de que empresas cíclicas são mais impactadas por variações na economia brasileira, uma vez que os resultados obtidos por meio da correlação canônica mostram que os indicadores econômico-financeiros das empresas do setor Cíclico estão mais correlacionados às variáveis macroeconômicas do que os indicadores das empresas Não Cíclicas. 
Palavras-chave: Consumo Cíclico. Consumo Não Cíclico. Variáveis Macroeconômicas. Indicadores de desempenho.

\begin{abstract}
All companies are influenced by macroeconomic variables, more or less sharply, as they are subject to the economic conditions of the regions where they operate. Thus, this reasoning is no different for companies that sell goods and services to end users, such as companies belonging to the consumption sector Cyclical (production and sale of durable goods) and Non-Cyclical (production and sale of non-durable goods) sector of BM\&FBovespa). In light of the Business Cycle Theory, the aim of this study was to assess the impact of macroeconomic variables on the financial indicators of companies in the Consumer Cyclical sector and Non-Cyclical BM\&FBovespa, since they have to companies in the first sector are more affected by economic fluctuations than companies in the second sector. In this sense, there was a quantitative, descriptive and analysis of documentary data. The study used calculation of canonical correlation coefficients, using statistical software SPSS (Statistical Package for Social Sciences). The survey sample consisted of 103 companies that negotiate their roles in the BM\&FBovespa, divided into the sectors of Consumer Cyclical (64 companies) and Consumer Non-Cyclical (39 companies). The study's findings point to an acceptance of the theory that cyclical companies are more impacted by changes in the Brazilian economy, since the results obtained by the canonical correlation indicates that the economic-financial indicators of Cyclical sector companies are more correlated to macroeconomic variables than the indicators of the companies not Cyclical.
\end{abstract}

Keywords: Cyclical Consumption. Consumer Cyclical not. Macroeconomic Variables. Performance Indicators.

\title{
1 INTRODUÇÃO
}

A economia brasileira vem enfrentando uma série de variações em seus indicadores macroeconômicos nos últimos anos, principalmente no Produto Interno Bruto (PIB), que mede o crescimento da economia de forma geral; na taxa de câmbio, que é taxa em que se convertem as transações em moeda estrangeira; na taxa do Sistema Especial de Liquidação e Custódia (SELIC), taxa básica de juros da economia brasileira; e na inflação, medida por meio de indicadores que expressam o aumento dos preços de produtos e serviços em determinada região e período (Banco Central do Brasil, 2016; IBGE, 2016).

Essas variações constantes na economia levam a inúmeras incertezas por parte das famílias e empresas. Incertezas quanto ao desempenho da economia tendo por base os aumentos da inflação, a redução do crescimento e a elevação do desemprego, por exemplo. Essas incertezas afetam as decisões de consumo das famílias, que podem preferir guardar dinheiro em poupanças ao invés de gastar com bens de consumo. No campo empresarial, os investimentos ficam comprometidos, uma vez que as empresas tendem a cortar opções de aumento da capacidade produtiva em períodos de queda na atividade econômica (Haddow, Hare, \& Hooley, 2013; Costa, 2014).

Em se tratando da Bolsa de Valores, Mercadorias e Futuros de São Paulo (BM\&FBovespa), um dos setores de atividades que está mais vulnerável às variações macroeconômicas é o de Consumo Cíclico. Em teoria, as receitas das empresas desse setor são diretamente afetadas por flutuações na economia, principalmente em períodos de recessão ou expansão econômica. Estão incluídas nesse grupo as companhias que produzem e comercializam bens duráveis, cujo faturamento varia conforme o nível de renda a curto prazo do mercado consumidor, uma vez que são bens que possuem grande elasticidade-renda, isto é, efeito da renda sobre o consumo (Pindyck \& Rubinfeld, 2009; Calixto, Oliveira, \& Kretzer, 2015). 
Outro grupo que representa as empresas que têm como principal atividade econômica a produção e/ou comercialização de bens de consumo é o setor de Consumo Não Cíclico. Pode ser definido, em teoria, como o menos afetado por variações macroeconômicas. As organizações enquadradas nesse setor têm como produto principal os bens de consumo não duráveis, como alimentos, bebidas, materiais de limpeza e higiene e etc. Os produtos e serviços dessas companhias não sofrem o efeito da elasticidade-renda, pois mesmo que hajam variações na renda da população, o consumo de tais bens e serviços tende a se manter estável (Vasconcellos \& Garcia, 2014; Calixto et al., 2015).

Estudos na área de variações macroeconômicas de um país são feitos desde o início do século XX. Tal área pode ser caracterizada pela Teoria dos Ciclos Econômicos, que propõe que a atividade econômica dos países sofre flutuações no nível do produto. Não existe um consenso entre os autores desse ramo de pesquisa que explique tais variações, mas as vertentes mais aceitas entre os estudiosos são de que ofertas de moeda (renda) e fatores não monetários, como produtividade e trabalho, são os motivos que mais propagam essas flutuações (Santos, Teixeira \& Dalmacio, 2008).

Conforme afirmam Santos et al. (2008), um dos primeiros estudiosos desse fenômeno foi Wesley Clair Mitchell, que publicou relevantes trabalhos a respeito do tema. A ideia de que ciclos econômicos podem afetar o desempenho das empresas foi uma das principais vertentes de pensamento de Mitchell. $O$ autor acreditava que o setor de atuação de cada organização fazia com que ela fosse mais ou menos afetada por esses ciclos (Mitchell, 1927; Santos et al., 2008).

Estudos internacionais recentes mostram que a área de ciclos econômicos ainda é objeto de pesquisa. Enqvist, Graham, e Nikkinen (2014) analisaram o impacto da gestão de capital de giro na rentabilidade de algumas empresas finlandesas durante variados ciclos de negócios e descobriram que condições macroeconômicas apresentam influências mensuráveis sobre a relação capital de giro/rentabilidade. Já Frösén, Jaakkola, Churakova e Tikkanen (2016) demonstraram em seu trabalho a respeito de empresas que possuem ênfase no relacionamento com clientes a longo prazo (business-to-business) que variações macroeconômicas têm uma influência notável no desempenho dessas organizações.

Ao se estudar a relação entre agregados macroeconômicos e desempenho econômicofinanceiro, é importante que se conheça os indicadores que expressam o desempenho de uma organização. Para tal procedimento utilizam-se técnicas conhecidas como análise de balanços ou análise das demonstrações contábeis, que é o caminho para que sejam extraídas informações de uma empresa para a tomada de decisões. Com base nos dados contidos nas demonstrações, a análise de balanços produz informações que serão úteis para um processo mais fundamentado de análise da situação econômico-financeira de uma empresa e consequentemente para a tomada de decisão por parte dos administradores (Matarazzo, 2008).

Depois de elaboradas várias pesquisas sobre o tema, verificou-se a escassez de trabalhos que analisam a relação das variáveis macroeconômica PIB, taxa de câmbio, taxa Selic e inflação com o desempenho das empresas do setor de Consumo Cíclico e Não Cíclico listadas na BM\&FBovespa. No contexto abordado, o problema de pesquisa que se coloca no presente estudo é: Qual o impacto das variações macroeconômicas no desempenho econômico-financeiro das empresas do setor de Consumo Cíclico e Não Cíclico listadas na BM\&FBovespa entre os anos de 2008 e 2015?

A partir do contexto abordado, tem-se que variações no desempenho da economia podem levar a variações no desempenho das empresas e, especialmente quando as curvas econômicas apresentam quedas, a geração de empregos e distribuição de renda pode ficar comprometida (Enqvist et al., 2014). Como contribuição social, o presente trabalho busca analisar como o desempenho das empresas de consumo no Brasil é afetado por variações macroeconômicas e se isso representa riscos para a população em idade economicamente ativa que busca por emprego.

Em relação às contribuições práticas do estudo, busca-se por meio deste fornecer um parâmetro de análise para gestores e administradores de empresas que se enquadrem no setor de Consumo Cíclico e Não Cíclico. Busca-se, também, auxiliar para a redução de 
incertezas em futuros planejamentos e modificar as áreas da organização que merecem destaque, conforme aconteçam variações na atividade econômica do país.

Para atender ao objetivo do trabalho, que foi o de verificar o impacto das variáveis macroeconômicas nos indicadores econômico-financeiros das empresas do setor de Consumo Cíclico e Não Cíclico da BM\&FBovespa, o presente estudo está dividido em seções, que compreendem: introdução; fundamentação teórica, que descreve sobre a teoria dos ciclos econômicos e estudos relevantes; método e procedimentos da pesquisa; análise dos dados e, na última seção, são apresentadas as considerações finais.

\section{FUNDAMENTAÇÃO TEÓRICA}

O presente referencial teórico se pauta na explicação da Teoria dos Ciclos Econômicos e na descrição de alguns estudos relevantes para a elaboração deste trabalho.

\subsection{Teoria dos ciclos econômicos}

Os "ciclos de negócios", "ciclos econômicos" ou business cycles podem ser definidos como flutuações na atividade econômica de uma nação em uma vasta gama de variáveis macroeconômicas, tais como produtos, empregos, preços, consumo, investimento e inovações tecnológicas (Long \& Plosser, 1983). Conforme explicam Santos et al. (2008), não existe um consenso entre os autores clássicos desse ramo de pesquisa que explique tais variações. As vertentes mais aceitas entre os estudiosos são de que ofertas de moeda (renda da população), investimentos, produtividade, trabalho, inovações tecnológicas e variações externas à economia, tais como alterações climáticas, são os motivos que mais propagam os ciclos.

Esforços sérios para que se explicassem crises de negócios e depressões econômicas começaram em meados do século XVIII, em meio às flutuações violentas do comércio após as Guerras Napoleônicas. Durante mais de um século, a Europa ocidental ficou mergulhada em intervalos de economia especulativa, mercados saturados e epidemia de falência, porém nessa época nenhuma ideia conclusiva de que isso se tratava de uma tendência que se repetiria muitas vezes mais tarde havia sido elaborada (Mitchell, 1927).

A partir do século XIX, Karl Marx e Adam Smith, filósofos políticos, que possuíam um vasto conhecimento econômico, passaram a prestar atenção aos movimentos econômicos, nas variações rítmicas do comércio e formularam as primeiras questões a respeito de ciclos de negócios. Tais formulações serviram de base para que autores como Mitchell (1913 e 1927), Schumpeter (1939), Burns e Mitchell (1946), Lucas (1977), Kydland e Prescott (1982 e 1990) e Long e Plosser (1983), além de outros, pudessem desenvolver seus estudos a respeito de ciclos econômicos e consolidar esse ramo como uma área relevante para pesquisas (Mitchell, 1927; Schumpeter, 1939).

Um dos mais antigos e influentes autores que estudou ciclos econômicos a fundo e tentou entender as origens e causas desse fenômeno foi Wesley Clair Mitchell. Para o autor, a característica crucial de uma economia capitalista moderna é que tudo gire em torno da moeda, ou seja, a produção somente é realizada se há expectativa de lucro por parte das empresas, com a venda de tais produtos. Sem a geração de lucros, a produção diminui, aumenta o desemprego e se instala uma crise generalizada. Em épocas de retração da atividade econômica, empresas vão à falência, ativos são liquidados e prepara-se o terreno para uma nova recuperação, prosperidade, novas crises e novas depressões na economia (Mitchell, 1913; Sherman, 2001).

Como um aprofundamento de suas primeiras impressões a respeito de business cycles, Mitchell publica outro livro, em 1927, em que busca explicar com mais clareza o problema envolvendo ciclos econômicos e suas configurações. De acordo com Mitchell, existe uma sucessão de fatores que levam a variações na atividade econômica de um país. Tais fatores começam com períodos de prosperidade, que levam a crises pelo mau planejamento das empresas, governo e famílias, passando assim por períodos de recessão e depressão da atividade econômica, que, depois de algum tempo, abrirão espaço para condições que conduzirão a uma nova recuperação, para que o ciclo se reinicie. 
Schumpeter (1939), em seu livro a respeito de ciclos de negócios, traz uma visão complementar à de Mitchell (1927), a respeito das causas desse fenômeno. Para ele, além de fatores internos do sistema econômico, como alterações no gosto dos consumidores, na quantidade ou qualidade da produção e modificação no fornecimento de commodities, por exemplo, existem os fatores externos à economia que são causadores dos ciclos, tais como o clima, descoberta de metais preciosos, terras inexploradas, abertura de novos países, entre outros, que foram causadores dos ciclos de negócios em épocas passadas.

Alguns anos depois, Arthur Frank Burns e Wesley Clair Mitchell (1946), por meio da prerrogativa de que ciclos de negócios duram de um a dez ou doze anos e não são divisíveis em ciclos mais curtos de caráter similar, procuram mensurar ciclos de negócios por meio de uma exposição detalhada dos métodos de medição do comportamento cíclico. Os autores também elaboraram uma pesquisa utilizando esses mesmos métodos para acompanhar possíveis mudanças no comportamento das variáveis macroeconômicas ao longo do tempo (Burns \& Mitchell, 1946; Koopmans, 1947).

Neste trabalho, Burns e Mitchell reforçam o enunciado de que ciclos econômicos são um tipo de flutuação encontrada na atividade econômica global dos países, que organizam seus trabalhos em empresas e que visam especificamente o lucro. Um ciclo consiste em variações que acabam por afetar todos os setores de uma economia e sempre acontecem de forma semelhante: prosperidade, que levam a crises, depois recessões e depressões, para novamente haver períodos de prosperidade e expansão, crises, recessões e assim por diante (Burns \& Mitchell, 1946).

Após criticas de Koopmans (1947), de que o trabalho de Burns e Mitchell foi elaborado para que determinadas hipóteses fossem aceitas como verdadeiras, o ramo de ciclos de negócios deixou de ser uma área ativa em pesquisa macroeconômica nas décadas seguintes. Prevaleceu o modelo Keynesiano de que choques de oferta e demanda são os causadores de ciclos de negócios. Entretanto, nos anos 70, surge Robert E. Lucas, autor que revoluciona os estudos em macroeconomia com o postulado de que fatores monetários são os principais causadores dos ciclos econômicos, corroborando as teorias do modelo Keynesiano (Santos et al., 2008).

Outros autores que se destacaram na explicação de business cycles foram Finn Kydland e Edward C. Prescott. Em 1982, esses autores publicaram um trabalho que altera novamente a interpretação dos ciclos econômicos. Com a utilização de dados trimestrais da economia norte-americana pós-guerra e modelos estatísticos inovadores para a época, que consideravam principalmente o time-to-build (tempo que um bem de capital leva para ser construído), Kydland e Prescott buscaram explicar as variações cíclicas de um conjunto de séries temporais econômicas.

Seguindo na mesma linha de raciocínio de Lucas e Kydland e Prescott, Long e Plosser (1983) também afirmam que choques de oferta e demanda são os mecanismos que mais propagam os ciclos, uma vez que incrementos adicionais e inesperados na renda da população fazem com que a busca por bens duráveis e não duráveis aumente. Por meio disso, a produção se ajusta para que não faltem nem sobrem produtos no mercado.

Outra mudança significativa no entendimento de ciclos de negócios adveio com o trabalho de Long e Plosser (1983). Os estudiosos são os primeiros a utilizarem a expressão Real Business Cycles (Teoria dos Ciclos Reais de Negócios) em seus trabalhos. Tal Teoria enfatiza que existem grandes flutuações aleatórias na taxa de mudança tecnológica e, a partir disso, indivíduos racionalmente alteram seus níveis de trabalho e consumo. Logo, choques de oferta e produtividade causados por variações tecnológicas são as principais determinantes das variações econômicas de um país, e não nível de preços e oferta de moeda, como defendia a Teoria dos Ciclos Econômicos anterior (Long \& Plosser, 1983; Mankiw, 1989).

A partir desse trabalho, consolidou-se a nova teoria a respeito de ciclos de negócios e outros pesquisadores seguiram a nova vertente de estudos. Mankiw (1989) enfatiza que essa nova teoria não fornece uma explicação plausível de flutuações econômicas e que, portanto, não deve ser utilizada por decisões políticas para avaliar os efeitos das políticas macroeconômicas propostas. Na visão de Plosser (1989), apesar de a Teoria dos Ciclos Reais de Negócios estar enraizada na análise de choques tecnológicos ou de produtividade, não 
pode se prender apenas a isso, pois existem outros fatores que também interferem na atividade econômica de uma nação.

\subsection{Estudos relevantes}

Santos et al. (2008) elaboraram um estudo que teve como objetivo analisar a relação entre os ciclos econômicos no Brasil e o desempenho econômico-financeiro das companhias de capital aberto no país. A amostra foi composta por todas as empresas listadas na Bovespa entre o primeiro trimestre de 1995 e o último trimestre de 2005. Como variável macroeconômica relacionada, foi utilizado o PIB real per capita. Já, para medir o desempenho econômico-financeiro das empresas, utilizou-se um conjunto de nove indicadores, divididos entre índices de liquidez, endividamento e estrutura de capital, rentabilidade e lucratividade, e também de volatilidade. Foram utilizados testes de correlação cruzada para medir o grau de interação entre os ciclos econômicos e o desempenho das empresas. Conclui-se, a partir de tais análises, que o setor Financeiro foi o que mais apresentou relação com o ciclo econômico. Indica que tal setor influencia diretamente no PIB. Outra verificação do estudo é que os indicadores de Rentabilidade do Patrimônio Líquido e Margem Operacional foram os que mais apresentaram correlação com PIB e em alguns setores, grande correlação, como na Siderurgia, Mineração e Metalurgia. Os outros indicadores apresentaram pouca ou nenhuma correlação com o ciclo econômico medido pelo PIB.

$\mathrm{O}$ estudo de Bastos, Nakamura e Basso (2009) teve como objetivo verificar os determinantes da estrutura de capital em companhias abertas da América Latina, levando em conta os fatores específicos da empresa e também fatores macroeconômicos e institucionais. Para tal, utilizaram como base 388 empresas de capital aberto de cinco das sete maiores economias da América Latina mensuradas pelo PIB de 2005 (México, Brasil, Argentina, Chile e Peru). As conclusões do estudo assinalaram que os índices de liquidez corrente e rentabilidade do ativo foram os fatores específicos da empresa que ajudaram a determinar sua estrutura de capital. Com relação aos fatores macroeconômicos e institucionais, a variável crescimento do PIB foi a mais relevante. Apresentou uma relação negativa com o endividamento total das companhias, uma vez que em tempos de crescimento econômico as empresas tendem a dispor de mais recursos internos para financiar seus investimentos.

Costa, Schmitt, Leite e Silva (2011) buscaram evidenciar em seu trabalho de que forma variáveis macroeconômicas influenciaram o nível de caixa das empresas brasileiras de capital aberto listadas na BM\&FBovespa. Para tal análise, os autores utilizaram as demonstrações contábeis de 82 empresas escolhidas aleatoriamente dentre as que negociaram ações na BM\&FBovespa, entre os anos de 2002 e 2009, em comparação com as variáveis macroeconômicas PIB, taxa SELIC e IPCA (Índice de Preços ao Consumidor Amplo). Ao final do estudo, os autores constataram numa análise estatística descritiva preliminar uma correlação negativa entre o nível médio de disponibilidades e as variações do IPCA e da taxa SELIC. Após a aplicação dos testes estatísticos, confirmou-se que tanto o IPCA, como a taxa SELIC e o PIB foram significativos para determinar o nível de disponibilidades das empresas.

O trabalho elaborado por Costa e Gomes (2011) objetivou a análise da influência dos ciclos econômicos em relação ao desempenho das empresas brasileiras de capital aberto. A amostra dessa pesquisa foram as empresas de capital aberto no Brasil, referentes aos períodos de 1986 a 2008, chegando a um total de 5.581 observações. Esse período foi escolhido por representar grandes crises financeiras mundiais, bem como as inúmeras variações nos planos econômicos brasileiros. O desempenho das empresas foi medido pela variável dependente ROA (lucro líquido em relação aos ativos). Foi utilizado o modelo estatístico para verificar a relação entre o desempenho e as variações macroeconômicas. A partir das observações, os autores concluíram que o efeito firma (características individuais de cada empresa) ainda é a maior responsável pela parte mais relevante do desempenho das organizações, embora grandes períodos de tempo tendam a fazer com que as variáveis macroeconômicas possuam maior poder de explicação sobre a firma individualmente. Além disso, o efeito ano e efeito ramo de negócios também foram relevantes no desempenho das companhias. 
Coelho (2012), em sua dissertação a respeito da relação entre indicadores de desempenho e variáveis macroeconômicas, objetivou investigar como variações na taxa de câmbio, PIB, inflação e taxa de juros impactam no nível de liquidez corrente das empresas. A amostra da pesquisa compreendeu as empresas listadas na BM\&FBovespa que tinham ações negociadas entre o período de 2003 e 2011 e que não eram pertencentes ao setor financeiro e de seguros. Foram coletados os dados trimestrais de 141 empresas, de 13 setores de atividades distintas. Como conclusão, os resultados obtidos pela autora mostram que o nível de liquidez das empresas analisadas é impactado por variações macroeconômicas. Além disso, verificou-se que as variáveis PIB e taxa de juros (SELIC) correlacionam-se aos índices de liquidez corrente de maneira positiva, ao passo que as variáveis câmbio e inflação se relacionam de forma negativa.

Em seu estudo, intitulado "A relação existente entre os lucros das empresas de capital aberto e das variáveis macroeconômicas", Fabris e Fontana (2012) analisaram a relação de curto e longo prazo existente entre as variáveis macroeconômicas e as séries dos lucros trimestrais (lucro operacional, líquido e por ação) das principais empresas brasileiras listadas na BM\&FBovespa. Como base nesse estudo foram utilizados os dados das empresas Ambev, BR Food's, Gerdau, Petrobras, Souza Cruz e Vivo, entre o primeiro trimestre de 2000 e o último de 2010. Como resultado, observou-se que os lucros das empresas e as variáveis macroeconômicas tendem a se equilibrar no longo prazo, principalmente o lucro líquido e operacional. Por meio desse estudo, estimaram-se parâmetros para correção de erros que contribuem para que sejam realizadas previsões de lucros em curto prazo.

Albuquerque, Silva e Maluf (2014) elaboraram um estudo com o objetivo de verificar se há relação entre a previsão de faturamentos futuros das empresas siderúrgicas brasileiras contra informações macroeconômicas, como PIB, taxa SELIC e inflação. Como amostra, foram utilizadas quatro empresas siderúrgicas nacionais: Gerdau, CSN (Companhia Siderúrgica Nacional), Usiminas e Vicunha, com análises entre o segundo trimestre de 2002 e o último de 2010. A metodologia utilizada no estudo é conhecida por ARMAX (Modelo Autorregressivo de Médias Móveis), e tem por finalidade assegurar que todas as variáveis exógenas (PIB, Inflação e taxa SELIC) possam ser consideradas simultaneamente em comparação à variável endógena dependente (faturamento). Como resultado, os autores apuraram que a taxa SELIC é a variável macroeconômica que mais influi no faturamento futuro das empresas do setor siderúrgico, uma vez que altas taxas de juros freiam investimentos no setor, enquanto taxas de juros mais baixas tendem a fazer com que os investimentos cresçam. As variáveis PIB e inflação, embora menos significativas, também influenciaram na expectativa de faturamento das empresas.

Como pesquisa recente, tem-se o trabalho de Lopes, Costa, Carvalho e Castro (2016), que teve por objetivo analisar o comportamento do valor de mercado das empresas brasileiras de capital aberto, em relação à situação econômico-financeira das mesmas durante duas grandes crises financeiras mundiais (2008 e 2012). Ao final da pesquisa, os autores concluíram que a relação do valor de mercado com o Patrimônio Líquido (PL) das empresas se comportou de forma diferente nos dois anos analisados. Em 2008, empresas que possuíam uma variação de mercado em relação ao PL abaixo da média apresentaram uma liquidez maior, um endividamento menor e lucratividade menor do que empresas que tinham variação de mercado em relação ao PL acima da média. Em 2012 inverteram-se os resultados, ou seja, empresas que possuíam uma variação de mercado em relação ao PL abaixo da média tiveram liquidez menor, endividamento maior e lucratividade maior do que empresas acima da média. A partir daí os autores destacam que empresas que possuíam maior alavancagem financeira em 2008 foram melhores avaliadas pelo mercado naquele ano, ao passo que empresas que tiveram maior liquidez foram as com maior valor de mercado em 2012.

\section{MÉTODO E PROCEDIMENTOS DA PESQUISA}

Quanto à abordagem do problema, esta pesquisa classifica-se como quantitativa, por se valer de técnicas estatísticas como coeficientes e índices. Silva (2010) coloca a ideia de pesquisa quantitativa aquela que se utiliza de técnicas de estudo sofisticadas, como o emprego 
aprimorado de estatística. Por esse motivo, a matemática assume lugar de destaque dentro das investigações que são classificadas como quantitativas (Silva, 2010).

Em relação aos objetivos propostos, a presente pesquisa caracteriza-se como descritiva. Para Silva (2010), uma pesquisa descritiva tem como principal objetivo estabelecer relações entre variáveis, a partir das características de determinada população ou fenômeno. Nesse tipo de pesquisa, existem técnicas padronizadas para a obtenção dos dados necessários e é de fundamental importância que o pesquisador tenha certo grau de responsabilidade, para que a pesquisa apresente validade científica.

Este estudo é definido como uma pesquisa documental. Tal procedimento baseia-se em materiais que não receberam qualquer tipo de tratamento por parte de estudiosos e por isso podem ser moldados com base no objetivo que a pesquisa pretende atingir. Nesse tipo de pesquisa, o objetivo é selecionar, tratar e interpretar a informação em seu estado bruto, buscando extrair dela algum sentido e atribuir-Ihe algum valor (Raupp \& Beuren, 2014).

A população ou universo da presente pesquisa são todas as 143 empresas que compõe os setores de Consumo Cíclico e Não Cíclico da BM\&FBovespa, segundo o relatório de classificação setorial constante no website. Em relação à amostra dessa pesquisa, a mesma pode ser definida como não probabilística. Desse modo, a amostra da presente pesquisa enquadra elementos da população das empresas dos setores de Consumo Cíclico e Não Cíclico da BM\&FBovespa.

No mês de agosto de 2016, existiam 64 companhias listadas no setor econômico de Consumo Cíclico que negociavam suas ações na BM\&FBovespa e que tinham as demonstrações contábeis publicadas conforme exige a legislação pertinente a esse tipo de organização. Tais empresas são classificadas nesse setor porque seu faturamento varia, em tese, de acordo com o desempenho da economia em que estão inseridas. Trata-se de empresas que produzem bens de consumo duráveis e que não têm prioridade de consumo em caso de uma baixa na renda da população.

Para o setor de Consumo Não Cíclico da BM\&FBovespa, a amostra constitui-se de 39 companhias listadas em agosto de 2016, subdivididas em oito subsetores de atuação, conforme atividade fim de cada uma. Tais empresas são enquadradas nesse setor, pois produzem e/ou comercializam bens de consumo não duráveis e que são de grande importância para o ser humano. Por esse motivo, independentemente da situação econômica da região em que estejam instaladas, o faturamento dessas organizações é menos impactado pelo ambiente econômico onde estejam inseridas.

O instrumento de coleta de dados da presente pesquisa visa à obtenção dos dados que constituirão os indicadores de desempenho econômico-financeiro das empresas dos setores de Consumo Cíclico e Não Cíclico, a partir dos dados publicados no sítio eletrônico da BM\&FBovespa. Foram coletados dados que formaram os nove indicadores de desempenho econômico-financeiro analisados no estudo, quais sejam: liquidez corrente, liquidez geral, grau de endividamento, composição do endividamento, margem EBIT (operacional), margem líquida, rentabilidade do ativo, rentabilidade do patrimônio líquido e variação da receita operacional líquida. Santos et al. (2008) e Stüpp (2015) mencionam que tais indicadores de análise das demonstrações contábeis são amplamente utilizados como variáveis explicativas para o desempenho econômico e financeiro das empresas.

Com o auxílio da base de dados Economáticaß foi feita a coleta dos dados que auxiliaram no cálculo das variáveis presentes na Tabela 3. Tais dados contemplaram o período de 2008 a 2015 e foram obtidos no mês de Julho de 2016.

A justificativa do período utilizado para proceder à coleta de dados da presente pesquisa dá-se pelo fato de que no final do ano de 2007 houve a sanção da Lei ํㅡ 11.638/07, que previu mudanças na Lei das Sociedades Anônimas (Lei no 6.404/76) e determinou que as empresas brasileiras adotassem as Normas Internacionais de Contabilidade, as IFRS (International Financial Reporting Standards). Tal acontecimento gerou algumas mudanças na forma de elaboração e divulgação das demonstrações contábeis de instituições financeiras e companhias de capital aberto no país (KPMG Auditores Independentes, 2008).

Em relação às variáveis macroeconômicas, que foram utilizadas como bases de medida das flutuações econômicas, estão o PIB, a inflação (medida pelo IPCA), a taxa Selic e a taxa 
de câmbio. Tais indicadores podem ser obtidos nas bases de dados de institutos oficiais, como o Instituto Brasileiro de Geografia e Estatística (IBGE) e o Banco Central do Brasil.

Dessa forma, os dados obtidos na presente pesquisa documental foram tabulados em planilhas eletrônicas do Microsoft Office Excel 2010, a fim de se organizá-los de forma sistemática que facilitasse as análises posteriores. Em seguida, os dados tabulados foram processados com a ajuda do software estatístico SPSS (Statistical Package for the Social Sciences), versão 23, para que se efetuasse os cálculos da correlação canônica entre as variáveis dependentes e independentes do estudo.

O método estatístico utilizado foi a correlação canônica, como definem Hair, Anderson, Black, Babin e Tatham (2009). É uma extensão lógica de uma análise feita por meio da regressão linear múltipla (relação entre uma única variável dependente com duas ou mais variáveis independentes). Na correlação canônica, o objetivo é correlacionar simultaneamente diversas variáveis dependentes métricas (variáveis que sofrem influência de outras e são mensuradas de forma quantitativa) com variáveis independentes (causadoras de mudanças em relação às variáveis dependentes), também métricas. Esse método de dependência é a técnica mais geral, por meio da qual todas as demais derivam (Fávero, Belfiore, Silva, \& Chan, 2009; Hair et al., 2009).

\section{ANÁLISE DOS DADOS}

Nesta seção apresenta-se a descrição (em forma de tabelas) e a análise dos dados que foram obtidos por meio da aplicação do teste de correlação canônica das variáveis. Esse teste consistiu no cálculo do coeficiente de correlação canônica e o nível de significância ( $p$-value) do grupo de variáveis macroeconômicas em relação aos indicadores econômico-financeiros das empresas dos setores de Consumo Cíclico e Não Cíclico da BM\&FBovespa. Na Tabela 1 observa-se a correlação canônica das variáveis macroeconômicas elencadas no estudo com o grupo de variáveis de desempenho das empresas do setor de Consumo Cíclico.

A partir da análise da Tabela 1, verifica-se que foram calculadas quatro combinações lineares diferentes pelo SPSS (Coluna 1), que representam o grupo de variáveis macroeconômicas (IPCA, SELIC, Câmbio e PIB). A coluna Autovalor e a coluna Wilks Lambda indicam a matriz de covariância (dependência) de cada variável responsável pela correlação entre elas (Magro, 2012). O p-value, por sua vez, indica a significância da combinação linear, que, de acordo com Hair et al. (2009), é ao nível de 0,05 (5\%).

Tabela 1

Correlação canônica das variáveis macroeconômicas com o grupo de desempenho econômico-financeiro das empresas do setor de Consumo Cíclico

\begin{tabular}{c|c|c|c|c|c}
\hline & $\begin{array}{c}\text { Correlação } \\
\text { Canônica }\end{array}$ & Autovalor & $\begin{array}{c}\text { Wilks } \\
\text { Lambda }\end{array}$ & D.F. & $\boldsymbol{P}$-value \\
\hline $\mathbf{1}$ &, 762 & 1,385 &, 314 & 36,000 &, 000 \\
$\mathbf{2}$ &, 389 &, 178 &, 749 & 24,000 &, 686 \\
$\mathbf{3}$ &, 266 &, 076 &, 883 & 14,000 &, 848 \\
$\mathbf{4}$ &, 224 &, 053 &, 950 & 6,000 &, 729 \\
\hline
\end{tabular}

Fonte: Dados da pesquisa.

Assim, observa-se que houve significativa correlação canônica da primeira combinação linear $(0,762)$ com um nível de significância ao nível de 0,05 ( $p$-value de 0,000). Logo, esse coeficiente de correlação canônica de 0,762 indica que existe uma considerável relação entre as variáveis do modelo. Na Tabela 2, verificam-se os coeficientes das variáveis canônicas provenientes da relação entre as variáveis macroeconômicas e os indicadores econômicofinanceiros das empresas do setor de Consumo Cíclico.

Conforme observado na Tabela 2, a maior correlação das quatro combinações lineares deu-se na primeira coluna. Portanto, a análise dos coeficientes da Tabela 2 será elaborada também com base na coluna um. Os coeficientes das demais colunas dizem respeito ao cálculo das outras três combinações lineares, porém, como o objetivo do modelo é apresentar 
as variáveis que tenham correlação máxima entre si, é utilizada apenas a primeira coluna na análise (Magro, 2012).

Tabela 2

Coeficientes para as variáveis canônicas dos indicadores macroeconômicos e econômico-financeiros das empresas do setor de Consumo Cíclico

\begin{tabular}{|c|c|c|c|c|c|}
\hline Grupos & Variável & \multicolumn{4}{|c|}{ Combinações lineares } \\
\hline \multirow{10}{*}{$\begin{array}{l}\text { Indicadores } \\
\text { econômico- } \\
\text { financeiros }\end{array}$} & & 1 & 2 & 3 & 4 \\
\hline & LC &,- 102 &,- 391 & ,629 &, 515 \\
\hline & LG & ,154 &,- 060 & ,053 &,- 281 \\
\hline & GE &,- 001 &,- 153 &,- 083 &,- 351 \\
\hline & CE & ,048 &,- 128 &,- 220 & ,275 \\
\hline & MG.EBIT & ,085 & ,353 & $-1,106$ & 201 \\
\hline & $M L$ & ,188 & ,125 & ,181 &,- 976 \\
\hline & RSA &,- 261 & 1,087 & , 183 & ,892 \\
\hline & RSPL &,- 066 &,- 333 & ,642 &,- 874 \\
\hline & VAR.ROL & ,973 &,- 436 & ,449 & ,278 \\
\hline & IPCA & ,464 & 1,204 & $-1,050$ &,- 150 \\
\hline Variáveis & SELIC &,- 058 &,- 106 & ,890 &,- 832 \\
\hline Macroeconômicas & CAMBIO & $-1,492$ &,- 466 & ,432 &, 532 \\
\hline & $\mathrm{PIB}$ &,- 498 & ,653 & ,516 &, 810 \\
\hline
\end{tabular}

Fonte: Dados da pesquisa.

Ao se relacionar-se as variáveis macroeconômicas com os indicadores econômicofinanceiros da coluna 1 (um), observa-se que há uma correlação diretamente proporcional entre a variável macroeconômica IPCA e os indicadores de desempenho econômicofinanceiros Liquidez Geral (LG), Composição do Endividamento (CE), Margem EBIT (MG. EBIT), Margem Líquida (ML) e Variação da Receita Liquida (VAR ROL). Essa última variável é mais relacionada, com um coeficiente de 0,973. Dessa forma, quanto maior ou menor for o IPCA, maior ou menor também serão os indicadores de desempenho econômico-financeiro (LG, CE, MG EBIT, ML, VAR ROL) (Fávero et al., 2009).

De forma semelhante, pode-se observar relação diretamente proporcional também entre os indicadores macroeconômicos taxa Selic, taxa de Câmbio e PIB com os indicadores econômico-financeiros Liquidez Corrente (LG), Grau de Endividamento (GE), Retorno Sobre o Ativo (RSA) e Retorno Sobre o PL (RSPL). Assim, quanto maior ou menor forem a taxa Selic, a taxa de Câmbio e o PIB, maior ou menor também serão os indicadores de desempenho econômico-financeiros (LC, GE, RSA, RSPL).

Como forma de comparação das correlações canônicas das empresas do setor de Consumo Cíclico com as empresas do setor de Consumo Não Cíclico, proceder-se-á agora às análises desse último grupo. Para tanto, está elencada na Tabela 3 a correlação canônica das variáveis macroeconômicas (IPCA, SELIC, Câmbio e PIB) com o grupo de variáveis de desempenho econômico-financeiro das empresas do setor de Consumo Não Cíclico.

Tabela 3

Correlação canônica das variáveis macroeconômicas com o grupo de desempenho econômico-financeiro das empresas do setor de Consumo Não Cíclico

\begin{tabular}{l|c|c|c|c|c}
\hline & $\begin{array}{c}\text { Correlação } \\
\text { Canônica }\end{array}$ & Autovalor & $\begin{array}{c}\text { Wilks } \\
\text { Lambda }\end{array}$ & D.F. & P-value \\
\hline $\mathbf{1}$ &, 590 &, 535 &, 534 & 36,000 &, 052 \\
$\mathbf{2}$ &, 314 &, 110 &, 819 & 24,000 &, 883 \\
\hline
\end{tabular}


Tabela 3 (continuação)

\begin{tabular}{c|c|c|c|c|c}
\hline & $\begin{array}{c}\text { Correlação } \\
\text { Canônica }\end{array}$ & Autovalor & $\begin{array}{c}\text { Wilks } \\
\text { Lambda }\end{array}$ & D.F. & P-value \\
\hline $\mathbf{3}$ &, 263 &, 074 &, 909 & 14,000 &, 903 \\
$\mathbf{4}$ &, 153 &, 024 &, 976 & 6,000 &, 926 \\
\hline
\end{tabular}

Fonte: Dados da pesquisa.

$\mathrm{Na}$ Tabela 3 foram gerados quatro conjuntos de combinações lineares pelo SPSS, que representam o grupo de variáveis macroeconômicas (IPCA, SELIC, Câmbio e PIB). Observa-se que houve correlação canônica moderada na primeira combinação linear $(0,590)$, menor do que o observado na maior combinação linear das variáveis macroeconômicas com empresas do setor Cíclico. Além disso, nenhuma combinação apresentou significância ao nível de 0,05 $(5 \%)$. A mais próxima chegou a 0,052 , contrariamente às informações observadas nas empresas cíclicas, que apresentaram uma significância com $p$-value de 0,000 na primeira combinação linear.

Apesar disso, o coeficiente de correlação canônica de 0,590 representa que existe uma moderada relação entre as variáveis do modelo, ou seja, as variações nos indicadores econômico-financeiros das empresas do setor de Consumo Não Cíclico são explicadas também pela primeira combinação linear do modelo, embora nenhuma delas atinja o nível de significância de $5 \%$.

$\mathrm{Na}$ Tabela 4, verificam-se os coeficientes das variáveis canônicas provenientes da relação entre as variáveis macroeconômicas e os indicadores econômico-financeiros das empresas do setor de Consumo Não Cíclico da BM\&FBovespa. A maior correlação das quatro combinações lineares deu-se na primeira coluna, observado o maior grau de correlação encontrado, apesar de não ter havido grau de significância na combinação.

Ao se relacionar as variáveis macroeconômicas com os indicadores econômicofinanceiros da coluna 1 (um), observa-se que há uma correlação diretamente proporcional entre as variáveis macroeconômicas IPCA e PIB e os indicadores de desempenho econômicofinanceiros Liquidez Geral (LG), Grau de Endividamento (GE), Margem EBIT (MG. EBIT), Margem Líquida (ML), Retorno sobre o PL (RSPL) e Variação da Receita Liquida (VAR ROL), essa última variável mais relacionada com as variáveis macroeconômicas, com um coeficiente de 0,826. Dessa forma, conclui-se que quanto maior ou menor for o IPCA e o PIB, maior ou menor também serão os indicadores de desempenho econômico-financeiros (LG, GE, MG EBIT, ML, RSPL e VAR ROL).

Além disso, pode-se observar relação diretamente proporcional também entre os indicadores macroeconômicos SELIC e Câmbio com os indicadores econômico-financeiros Liquidez Corrente (LG), Composição do Endividamento (CE) e Retorno Sobre o Ativo (RSA). Assim, quanto maior ou menor forem SELIC e o Câmbio, maior ou menor também serão os indicadores de desempenho econômico-financeiros (LC, CE e RSA).

Tabela 4

Coeficientes para as variáveis canônicas dos indicadores macroeconômicos e econômico-financeiros das empresas do setor de Consumo Não Cíclico

\begin{tabular}{c|c|c|c|c|c}
\hline Grupos & Variável & \multicolumn{4}{|c}{ Combinações lineares } \\
\hline & & $\mathbf{1}$ & $\mathbf{2}$ & $\mathbf{3}$ & $\mathbf{4}$ \\
& LC &,- 142 &, 166 & $-1,824$ &, 536 \\
Indicadores & LG &, 105 &,- 633 & 1,828 & $-1,291$ \\
econômico- & GE &, 146 &,- 456 &,- 826 &, 200 \\
financeiros & CE &,- 227 &, 309 & $-1,457$ &, 695 \\
& & & & & \\
\hline
\end{tabular}


Tabela 4 (continuação)

\begin{tabular}{c|c|c|c|c|c}
\hline Grupos & Variável & \multicolumn{4}{|c}{ Combinações lineares } \\
\hline & & $\mathbf{1}$ & $\mathbf{2}$ & $\mathbf{3}$ & $\mathbf{4}$ \\
& MG.EBIT &, 203 & $-1,071$ &,- 472 &,- 119 \\
Indicadores & ML &, 147 & 1,467 &, 352 & $-1,022$ \\
econômico- & RSA &,- 286 &, 442 &,- 660 & 1,588 \\
financeiros & RSPL &, 108 &,- 215 &,- 016 &,- 529 \\
& VAR.ROL &, 826 &, 304 &, 143 &, 275 \\
\hline \multirow{3}{*}{ Variáveis } & IPCA &, 334 &, 927 & $-1,111$ & 1,073 \\
Macroeconômicas & SELIC &,- 983 &,- 177 &,- 128 &,- 731 \\
& CAMBIO &,- 414 &, 036 & 1,779 &, 049 \\
\hline
\end{tabular}

Fonte: Dados da pesquisa.

Conforme evidenciado na literatura, os ciclos de negócios ou o desempenho de uma economia têm a capacidade de influenciar no desempenho das empresas que estão inseridas nesse ambiente, uma vez que muitos fatores macroeconômicos vão se sobrepondo e acabam por impactar no nível de atividade das organizações. As vertentes mais aceitas entre os estudiosos são de que ofertas de moeda (renda da população), investimentos, produtividade, trabalho, inovações tecnológicas e variações externas à economia, tais como alterações climáticas, são os motivos que mais propagam as variações macroeconômicas em um país (Long \& Plosser, 1983; Santos et al., 2008).

Assim como previsto pela teoria, flutuações macroeconômicas expressas por indicadores de inflação (IPCA), taxa de juros (SELIC), taxa de câmbio e PIB foram mais expressivas em empresas do setor de Consumo Cíclico do que nas de Consumo Não Cíclico. A partir da análise das Tabelas 1 e 3 observa-se uma correlação maior das variáveis macroeconômicas com empresas do setor Cíclico (0,762 contra 0,590 do setor Não Cíclico).

Os resultados encontrados no presente trabalho corroboram os resultados de alguns estudos e são contrários a outros encontrados na literatura. Para os indicadores de liquidez, Costa et al. (2011) evidenciaram uma relação negativa do nível de disponibilidades (que influencia nos indicadores de liquidez das empresas) com o IPCA. Coelho (2012) concluiu em seu estudo que os indicadores de liquidez das empresas correlacionam-se de forma positiva à taxa de juros e ao PIB e de forma negativa à taxa de câmbio e inflação, tal como na presente pesquisa.

Em relação aos indicadores de endividamento, o presente estudo não encontrou relação significante entre as variáveis macroeconômicas e tais indicadores. Bastos et al. (2009) também não observaram relação significativa das taxas de inflação com o endividamento contábil das empresas da América Latina, mas observaram que existe influência do PIB sobre o endividamento das companhias, assim como Dani, Padilha, Santos e Almeida-Santos (2016), os quais enfatizam que um dos principais fatores que influenciam na estrutura de capital das empresas é o PIB, uma vez que o crescimento econômico traz maiores disponibilidades de recursos internos para as empresas que se utilizam de mais capital próprio para seu financiamento.

Para os indicadores de rentabilidade e lucratividade (ML, MG EBIT, RSA, RSPL e VAR ROL), o presente estudo indica uma alta correlação das variáveis macroeconômicas com variação da receita líquida (VAR ROL), corroborando estudos anteriores que tendem a afirmar que existe relação entre a economia e os indicadores de desempenho econômico e financeiro das empresas, descritos abaixo.

Santos et al. (2008) identificaram relação positiva entre a rentabilidade dos ativos (RSA) e a margem operacional das empresas (MG EBIT) em relação ao PIB das empresas brasileiras de capital aberto. Indicam que se a economia tem um bom desempenho, isso afeta positivamente os resultados das empresas. Fabris e Fontana (2012) afirmam que as variáveis macroeconômicas e a lucratividade das empresas tendem a se equilibrar no longo prazo, ou 
seja, se a economia do país tem um bom desempenho, as empresas tendem a apresentar uma boa lucratividade. Já Albuquerque et al. (2014) apuraram que a taxa SELIC é a variável macroeconômica que mais influi no faturamento futuro das empresas do setor siderúrgico e as variáveis PIB e inflação, embora menos significativas, também influenciaram na expectativa de faturamento dessas empresas.

O estudo de Deleersnyder, Dekimpe, Sarvary e Parker (2003) corrobora os achados do presente trabalho. Os autores afirmam que bens de consumo duráveis (produzidos por empresas do Consumo Cíclico) tendem a ser menos consumidos em épocas de recessão econômica, uma vez que a população tende a concentrar seu consumo em bens de consumo não duráveis (produzidos por empresas do setor Não Cíclico), mais necessários à sobrevivência. Isso explica uma maior correlação da Variação da Receita Líquida em relação às variáveis macroeconômicas no setor de Consumo Cíclico do que no setor Não Cíclico.

\section{CONSIDERAÇÕES FINAIS}

O presente estudo teve como objetivo analisar o impacto das variações macroeconômicas no desempenho econômico e financeiro das empresas de Consumo Cíclico e Não Cíclico da BM\&FBovespa entre os anos de 2008 e 2015, a fim de verificar qual dos dois setores é mais impactado pelas variações da economia nacional e se a teoria a respeito dos setores se confirma em relação aos indicadores de desempenho.

A fim de melhor organizar as empresas que negociam seus papéis no mercado de capitais, a BM\&FBovespa utiliza a classificação setorial das mesmas, de acordo com a atividade principal geradora de receitas de cada uma, formando assim blocos de empresas que atuam de forma semelhante no mercado. Dentro desses setores estão o de Consumo Cíclico e de Consumo Não Cíclico, que têm como função principal a comercialização de bens e serviços ao consumidor final.

Conforme observado na literatura, empresas pertencentes ao setor de Consumo Cíclico (vestuário, calçados, automóveis, móveis, eletrodomésticos, entre outros) têm seu desempenho influenciado por variações na economia, seja por recessões ou expansões econômicas, uma vez que produzem ou vendem bens tidos como não de primeira necessidade ou que o consumo pode ser reduzido. Por outro lado, empresas pertencentes ao setor de Consumo Não Cíclico produzem bens não duráveis, tais como alimentos e bebidas e prestam serviços de assistência médica e hospitalar, que são tidos como de primeira necessidade e têm seu gasto pouco impactado pelo nível de renda da população, pois são consumidos mesmo em tempos de recessão econômica.

O estudo por meio da correlação canônica, que consiste em analisar a relação linear entre dois conjuntos de dados, apresentou resultados que comprovam a teoria de que empresas pertencentes ao setor de Consumo Cíclico são mais afetadas pelo desempenho da economia do que empresas do setor de Consumo Não Cíclico.

Quando correlacionados os indicadores econômico-financeiro das empresas do setor de Consumo Cíclico observou-se um na primeira combinação linear de 0,762 , com um nível de significância ao nível de 0,000 . Isso indica que a correlação é significante em termos estatísticos. Para o setor de Consumo Não Cíclico, a maior combinação linear foi de 0,590, porém sem significância estatística ao nível de $5 \%$.

Além disso, confirmou-se por meio da correlação canônica que a variação da receita operacional líquida foi a variável de desempenho das empresas mais impactada pelas variáveis macroeconômicas, com um coeficiente de correlação de 0,973 para o setor de Consumo Cíclico e de 0,826 para o Consumo Não Cíclico, o que confirma novamente um maior impacto de variáveis macroeconômicas sobre as receitas de empresas de Consumo Cíclico. Além disso, observa-se que outros indicadores importantes, que medem o desempenho empresarial, como a margem de lucros, não apresentou correlação expressiva em qualquer dos dois setores analisados neste estudo.

Com isso, deixa-se como sugestão para futuros estudos que pesquisadores busquem elencar outras variáveis de desempenho das empresas de Consumo Cíclico e Não Cíclico que possam ter relação com fatores macroeconômicos, tais como os indicadores de atividade 
(prazos médios de recebimento de vendas e pagamento de fornecedores, ciclo operacional e ciclo financeiro) e a análise dinâmica do capital de giro, entre outros. Além disso, sugere-se a replicação deste estudo em outros setores de empresas da BM\&FBovespa (materiais básicos, bens industriais, financeiro, saúde, telecomunicações, utilidade pública), a fim de verificar se existe relação entre o desempenho de tais empresas e a economia brasileira, tal como verificado neste estudo.

\section{REFERÊNCIAS}

Albuquerque, P. H. M., Silva, L. C., \& Maluf, Y. S. (2014) Estimação da influência de variáveis macroeconômicas sobre o faturamento de organizações siderúrgicas usando o ARMAX. Gestão \& Produção, 21(3), 648-659.

Banco Central do Brasil. Índices de inflação. Recuperado em 8 maio, 2016, de http://www.bcb.gov.br/pre/portalCidadao/indecon/indice_inflacao.asp?idPai=PORTALBCB

Bastos, D. D., Nakamura, W.T, \& Basso, L. F. C. (2009). Determinantes da Estrutura de Capital das Companhias Abertas na América Latina: um estudo empírico considerando fatores macroeconômicos e institucionais. Revista de Administração Mackenzie, 10(6), 47-77.

Burns, A. F., \& Mitchell, W. C. (1946). Measuring Business Cycles. New York: National Bureau of Economic Research Books.

Calixto, T. C., Oliveira, R., \& Kretzer, J. (2015). O comportamento das indústrias cíclicas brasileiras pós-real. Semana de Ciências Econômicas, Guarapuava, 16.

Coelho, L. B. (2012). Efeitos de variáveis macroeconômicas no nível de liquidez de empresas brasileiras. Dissertação de Mestrado, Fundação Getúlio Vargas, São Paulo, SP, Brasil.

Costa, A. E., Filho (2014). Incerteza e atividade econômica no Brasil. Economia Aplicada, 18, (3), 421-453.

Costa, C. T., \& Gomes, F. P. (2011). Análise da variação do desempenho de empresas brasileiras. Organizações em Contexto, 7(13), 85-105.

Costa, G. P. C. L., Schmitt, F. O., Leite, P. A. M., Filho, Silva, C. A. T. (2011) O reflexo das variáveis macroeconômicas no nível de caixa evidenciado pelas empresas brasileiras listadas na Bovespa. Anais Congresso ANPCONT, Vitória, ES, Brasil, 5.

Dani, A. C., Padilha, D., Santos, C. A. dos, \& Almeida-Santos, P. S. (2016). Effect of market timing in the capital structure of Latin America. Revista de Gestão, Finanças $e$ Contabilidade, 6(3), 143-159.

Deleersnyder, B., Dekimpe, M. G., Sarvary, M., \& Parker, P. M. (2003). Weathering tight economic times: the sales evolution of consumer durables over the business cycle. Quantitative Marketing and Economics, 2(4), 347-383.

Enqvist, J., Graham, M., \& Nikkinen, J. (2014). The impact of working capital management on firm profitability in different business cycles: Evidence from Finland. Research in International Business and Finance, 32, 36-49.

Fabris, T. R., \& Fontana, M. L. L. (2012). A relação existente entre os lucros das empresas de capital aberto e das variáveis macroeconômicas. Anais Congresso USP de Iniciação Científica em Contabilidade, São Paulo, SP, Brasil, 9. 
Fávero, L. P., Belfiore, P., Silva, F. L., \& Chan, B. L. (2009). Análise de dados: modelagem multivariada para tomada de decisões. Rio de Janeiro: Campus.

Frösén, J., Jaakkola, M., Churakova, I., \& Tikkanen, H. (2016). Effective forms of market orientation across the business cycle: A longitudinal analysis of business-to-business firms. Industrial Marketing Management, 52, 91-99.

Haddow, A., Hare, C., \& Hooley, J. (2013). Macroeconomic uncertainty: what is it, how can we measure it and why does it matter? Bank of England Quarterly Bulletin, p. Q2.

Hair, J. F., Anderson, R. E., Black, W. C., Babin, B. J., \& Tatham, R. L. (2009). Análise multivariada de dados (6a ed.). Porto Alegre: Bookman.

Instituto Brasileiro de Geografia e Estatística. Contas Nacionais. Recuperado em 27 março, 2016, de http://brasilemsintese.ibge.gov.br/contas-nacionais.html

Koopmans, T. C. (1947). Measurement without theory. The Review of Economics and Statistics, 29(3), 161-172.

KPMG. (2008). O Brasil e as normas internacionais de contabilidade (IFRS). Recuperado em 5 maio 2016, http://www.kpmg.com.br/publicacoes/audit/ifrs/folder_ifrs_perguntas_respostas.pdf

Kydland, F. E, \& Prescott, E. C. (1982). Time to build and aggregate fluctuations. Econometrica - Journal of the Economy Society, 50(6), 1345-1370.

Long, J. B. J., \& Plosser, C.I. (1983). Real business cycles. The Journal of Political Economy, 91(1), 39-69.

Lopes, P. F., Costa, D. F., Carvalho, F. M., \& Castro, L. G., Filho (2016). Desempenho econômico e financeiro das empresas brasileiras de capital aberto: um estudo das crises de 2008 e 2012. Revista Universo Contábil, 12(1), 105-121.

Lucas, R. E. (1976). Understanding Business Cycles. Kiel Conference on Growth Without Inflation, Kiel, Alemanha.

Magro, C. B. D. (2012). Utilidade do orçamento empresarial nas indústrias catarinenses sob a ótica da teoria da dependência de recursos. Dissertação de Mestrado, Fundação Universidade Regional de Blumenau, SC, Brasil.

Mankiw, N. G. (1989). Real Business Cycles: A new keynesian perspective. The Journal of Economic Perspectives, 3(3), 79-90.

Matarazzo, D. C. (2008). Análise financeira de balanços: abordagem básica e gerencial (6a ed.) São Paulo: Atlas.

Mitchell, W. C. (1913). Business Cycles. Berkeley: University of California Press.

Mitchell, W. C. (1927). Business Cycles: The Problem and Its Setting. New York: National Bureau of Economic Research Books.

Pindyck, R. S., \& Rubinfeld, D. L. (2009). Microeconomia (7a ed.). Madrid: Pearson Prentice Hall.

Plosser, C. I. (1989). Understanding real business cycles. The Journal of Economic Perspectives, 3(3), 51-77. 
Raupp, F. M., Beuren, I. M. (2014) Metodologia da pesquisa aplicável às ciências sociais. In I. M. Beuren (Org.) Como elaborar trabalhos monográficos em contabilidade (3a ed.). São Paulo: Atlas.

Santos, E. S. (2011) Full IFRS x Lei 11.638 (1 ${ }^{a}$ fase) $x$ Lei 6.404: impacto esperado nos resultados de 2010 a partir das empresas que se anteciparam. Anais Congresso USP de Contabilidade e Controladoria, São Paulo, SP, Brasil, 11.

Santos, F. M., Teixeira, A., \& Dalmacio, F. Z. (2008). Impacto das flutuações econômicas no desempenho das empresas: estudo intra-setorial sob a perspectiva da teoria dos ciclos econômicos. Anais Congresso ANPCONT, Salvador, BA, Brasil, 2.

Sherman, H. (2001). The Business Cycles Theory of Wesley Mitchell. Journal of Economic Issues, 35(1), 85-97.

Schumpeter, J. A. (1939). Business Cycles: A Theoretical, Historical, and Statistical Analysis of the Capitalist Process. New York: McGraw-Hill Book Company.

Silva, A. C. R. (2010). Metodologia da pesquisa aplicada à contabilidade: orientações de estudos, projetos, artigos, relatórios, monografias, dissertações, teses. Atlas.

Stüpp, D. R. (2015). Previsão de insolvência a partir de indicadores contábeis: evidências de empresas listadas na BM\&FBovespa nos anos 2004-2013. Dissertação de Mestrado, Universidade do Estado de Santa Catarina, SC, Brasil.

Vasconcellos, M. A. S., \& Garcia, M. E. (2014). Fundamentos de economia (5ª ed.). São Paulo: Saraiva. 